\title{
Zoonotic intestinal parasites of carnivores: A systematic review in Iran
}

\author{
Shahabeddin Sarvi ${ }^{1}$, Ahmad Daryani ${ }^{1}$, Mehdi Sharif ${ }^{1}$, Mohammad Taghi Rahimi ${ }^{2}$, Mohammad Hasan Kohansal ${ }^{3}$,
} Siavash Mirshafiee ${ }^{4}$, Abolghasem Siyadatpanah ${ }^{5}$, Seyed-Abdollah Hosseini ${ }^{5}$ and Shirzad Gholami ${ }^{1}$

1. Department of Parasitology and Mycology, Toxoplasmosis Research Center, Mazandaran University of Medical Sciences, Sari, Iran; 2. Department of Parasitology, School of Medicine, Shahroud University of Medical Sciences, Shahroud, Iran; 3. Department of Parasitology and Mycology, School of Medicine, Zanjan University of Medical Sciences, Zanjan, Iran; 4. Department of Husbandry, Qaemshahr branch of Islamic Azad University, Mazandaran, Iran; 5. Department of Parasitology and Mycology, School of Medicine, Mazandaran University of Medical Sciences, Sari, Iran. Corresponding author: Shirzad Gholami, e-mail: sgholami200@gmail.com

Co-authors: SS: shahabesarvi@yahoo.com, AD: daryanii@yahoo.com, MS: msharifmahdi@yahoo.com, MTR: rahimimt@gmail.com, MHK: kohansalhasan@gmail.com, SM: dr.mirshafiee@gmail.com, AS: asiyadatpanah@yahoo.com, SH: hosseini4030@gmail.com

Received: 06-09-2017, Accepted: 15-12-2017, Published online: 23-01-2018

doi: 10.14202/vetworld.2018.58-65 How to cite this article: Sarvi S, Daryani A, Sharif M, Rahimi MT, Kohansal MH, Mirshafiee S, Siyadatpanah A, Hosseini S, Gholami S (2018) Zoonotic intestinal parasites of carnivores: A systematic review in Iran, Veterinary World, 11(1): 58-65.

\begin{abstract}
Aim: Parasitic infections, especially of the zoonotic-parasitic type, are the most important health, economic, and social problems in developing countries, including Iran. The aim of this study was to review systematically the available data on gastrointestinal parasites of carnivores in Iran and their ability to infect humans.

Materials and Methods: Studies reporting intestinal parasites of carnivores were systematically collected from nine electronic English and Persian databases and Proceedings of Iranian parasitology and veterinary congresses published between 1997 and 2015. A total of 26 studies issued from 1997 to 2015 met the eligibility criteria.

Results: The pooled proportion of intestinal parasites of carnivores was estimated as $80.4 \%$ (95\% confidence interval $=70.2-88.8 \%$ ). The overall prevalence of gastrointestinal parasites in dogs, cats, foxes, and jackals were $57.89 \%$, $90.62 \%, 89.17 \%$, and 97.32\%, respectively. Dipylidium caninum (20.45\%), Toxocara spp. (18.81\%), Taenia hydatigena (15.28\%), Mesocestoides lineatus (11.83\%), Echinococcus granulosus (10\%), and Toxascaris leonina (8.69\%) were the most frequently observed parasites.

Conclusion: High prevalence rates of zoonotic intestinal parasites of carnivores particularly Echinococcus spp. and Toxocara spp. increase the risk of acquiring zoonotic infections such as cystic hydatid, alveolar cysts, and visceral or ocular larva migrants in Iranian people. Therefore, it is essential for public health centers to develop more effective control strategies to decrease infections rates in carnivores' populations.
\end{abstract}

Keywords: carnivores, intestinal parasites, zoonotic disease.

\section{Introduction}

Parasitic infections, particularly those capable of zoonosis, are the most important health, economic, and social problems in developing countries, including Iran. Carnivores are definitive or reservoirs hosts for more than 60 zoonotic parasites $[1,2]$. The presence of these animals in close contact with people constitutes a high potential risk of infection, especially for children due to their poor hygiene relative to adults and higher exposure to contact with contaminated soil containing parasite eggs or cysts. Further, farmers and ranchers who often work in agriculture and animal husbandry are at risk [1,3]. Several gastrointestinal parasites of canines particularly Toxocara spp., Ancylostoma spp., Echinococcus spp., Dipylidium spp., Giardia, and

Copyright: Sarvi, et al. Open Access. This article is distributed under the terms of the Creative Commons Attribution 4.0 International License (http://creativecommons.org/licenses/by/4.0/), which permits unrestricted use, distribution, and reproduction in any medium, provided you give appropriate credit to the original author(s) and the source, provide a link to the Creative Commons license, and indicate if changes were made. The Creative Commons Public Domain Dedication waiver (http://creativecommons.org/ publicdomain/zero/1.0/) applies to the data made available in this article, unless otherwise stated.
Cryptosporidium spp. are considered important in the public health area by the zoonotic potential that they present $[4,5]$.

Zoonotic parasites that are transmitted to humans can be divided into four groups: (i) Direct zoonotic parasites that infect humans directly from animals including: Giardia, Cryptosporidium, and Toxocara, (ii) saprozoonotic parasites that are transmitted through soil or water, for example, Ancylostoma spp. and Strongyloides stercoralis, (iii) meta-zoonotic parasites that humans acquire through invertebrate intermediate hosts including Fasciola spp. and Dipylidium caninum, and (iv) cyclo-zoonotic parasites that can infect humans through vertebrate intermediate hosts such as Echinococcus granulosus and Taenia spp. [5-8].

Infections with some of the aforementioned parasites cause symptoms and clinical manifestations in humans including hydatidosis, visceral larva migrans, coenurosis, creeping eruption, mesocestoidiasis, and dipylidiasis [1,9]. Among the above-mentioned zoonotic-parasitic infections, Iran is considered an important endemic area of hydatidosis. In addition, toxocariasis is a zoonotic 
disease with a documented high prevalence in this country [10]. Although numerous studies have been conducted in relation to the prevalence of gastrointestinal parasites in carnivores in Iran, there is no systematic review to analyze this data. Therefore, the major objective of the current systematic review was to determine the prevalence of gastrointestinal parasites in carnivores, and further, to describe the epidemiological status of zoonotic parasitic infections of carnivores in Iran.

\section{Materials and Methods}

\section{Database search}

Five English databases (PubMed, Scopus, Science Direct, Web of Science (ISI), and Google Scholar) and four Persian databases (Magiran, Scientific Information Database, Iran Medex, and Iran Doc) were searched for published articles about intestinal parasites of carnivores in Iran from 1997 to 2015. The language of data collection was limited to English and Persian. The keywords used alone or in combination were: "Intestinal parasite," "zoonotic parasites," "carnivores," “dogs," “cats," “foxes," "jackals," "prevalence," "helminth," "protozoa," and "Iran." All Iranian parasitology and veterinary congresses proceedings were carefully evaluated. To avoid missing any papers, all references from each article were systematically checked (Figure-1).

\section{Data extractions}

Extracted data from the studies included information about the year of publication, first author, province of the study, diagnostic method, sample size, number of positive samples, types of carnivorous, types of gastrointestinal parasites, and types of animal (domestic or stray). In addition, studies which were attributed to human, tissue, blood parasite, case report, and repetitive papers have been excluded.

\section{Statistical analysis}

The pooled proportion of carnivore intestinal parasitic infection, as well as, 95\% confidence interval (CI) was calculated for each study. A forest plot was used to visualize heterogeneity among the included studies. The size of every square indicated the weight of every study also the crossed lines illustrated CI. The heterogeneity was expected in advance, and statistical analyses including $\mathrm{I}^{2}$ and Cochrane's Q test (with a significance level of $p<0.1$ ) were used to quantify variations. The StatsDirect statistical software (http:// www.statsdirect.com) was used for analysis.

\section{Results}

A total of 26 studies in Iran, reporting for carnivorous intestinal parasites, fulfilled our inclusion criteria (Table-1) [11-34]. A total of 2,508 samples were analyzed, and the pooled proportion of carnivore intestinal parasites, in Iran, from 1997 to 2015 was

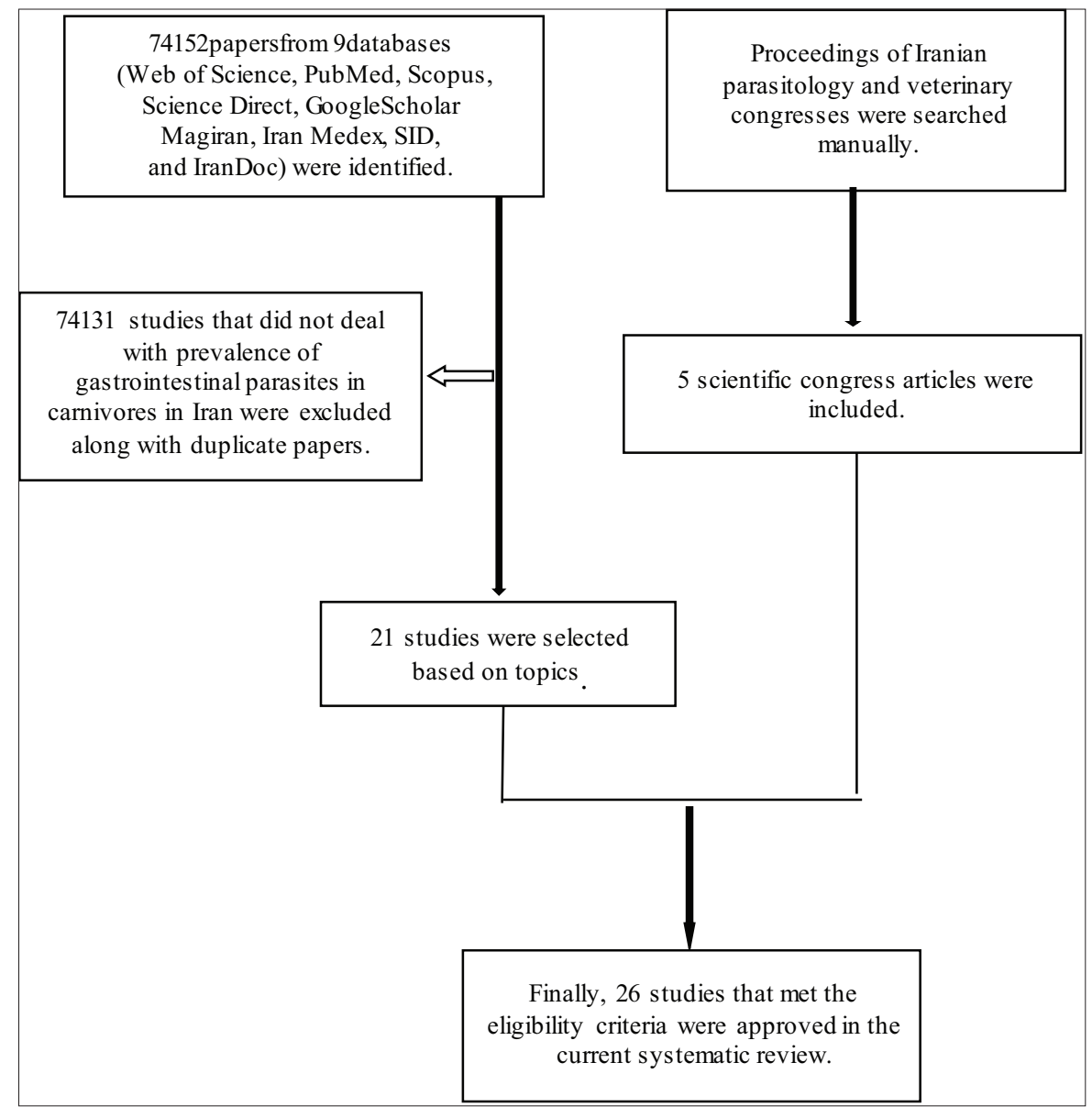

Figure-1: Flow diagram describing the study design process. 
Table-1: Details of the included studies of intestinal parasitic infections in carnivores in Iran.

\begin{tabular}{|c|c|c|c|c|c|c|c|c|}
\hline ID & Province of Iran & Animal & Domestic/Stray & $\begin{array}{l}\text { Diagnostic } \\
\text { method }\end{array}$ & $\begin{array}{l}\text { Sample } \\
\text { size }\end{array}$ & $\begin{array}{c}\text { Parasite positive } \\
\text { samples }\end{array}$ & Prevalence (\%) & Ref \\
\hline 1 & Isfahan & Dog & Stray & Parasitologic & 61 & 31 & 50.81 & [11] \\
\hline \multirow[t]{2}{*}{2} & Mazandaran & Jackals & Stray & Parasitologic & 45 & 42 & 93.33 & [12] \\
\hline & & Dog & Stray & Parasitologic & 30 & 24 & 80 & \\
\hline 3 & Kerman & Dog & Stray & Parasitologic & 22 & 14 & 63.63 & {$[13]$} \\
\hline 4 & Isfahan & Cat & Stray & Parasitologic & 113 & 109 & 96.46 & [14] \\
\hline 5 & Mazandaran & Cat & Stray & Parasitologic & 100 & 78 & 78 & [15] \\
\hline \multirow[t]{3}{*}{6} & Western & Jackals & Stray & Parasitologic & 10 & 10 & 100 & [3] \\
\hline & Azerbaijan/ & Fox & Stray & Parasitologic & 22 & 21 & 95.45 & \\
\hline & $\begin{array}{l}\text { Kurdistan/ } \\
\text { Kermanshah }\end{array}$ & Dog & Stray & Parasitologic & 83 & 74 & 89.15 & \\
\hline 7 & Fars & Cat & Stray & Parasitologic & 114 & 106 & 92.98 & [16] \\
\hline 8 & Isfahan & Cat & Stray & Parasitologic & 113 & 110 & 97.34 & [10] \\
\hline \multirow[t]{3}{*}{9} & Ardabil & Jackals & Stray & Parasitologic & 1 & 1 & 100 & [17] \\
\hline & & Fox & Stray & Parasitologic & 89 & 82 & 92.13 & \\
\hline & & Dog & Domestic & Parasitologic & 59 & 39 & 66.1 & \\
\hline 10 & Semnan & Dog & Stray & Parasitologic & 50 & 40 & 80 & [18] \\
\hline 11 & Western Azerbaijan & Dog & Stray & Parasitologic & 206 & 71 & 34.46 & [19] \\
\hline 12 & Razavi Khorasan & Cat & Stray & Parasitologic & 52 & 46 & 88.46 & [20] \\
\hline 13 & Eastern Azerbaijan & Fox & Stray & Parasitologic & 52 & 41 & 78.84 & [21] \\
\hline 14 & Eastern Azerbaijan & Dog & ND & Parasitologic & 100 & 41 & 41 & [22] \\
\hline 15 & Mazandaran & Dog & Stray & Parasitologic & 50 & 45 & 90 & [23] \\
\hline 16 & Isfahan & Dog & Stray & Parasitologic & 96 & 58 & 60.4 & [24] \\
\hline 17 & Razavi Khorasan & Dog & Stray & Parasitologic & 100 & 86 & 86 & [25] \\
\hline 18 & Ilam & Dog & Stray & Parasitologic & 65 & 54 & 83.07 & [26] \\
\hline 19 & Razavi Khorasan & Dog & Stray & Parasitologic & 100 & 84 & 84 & [27] \\
\hline 20 & Razavi Khorasan & Dog & Stray/Domestic & $\begin{array}{l}\text { Parasitologic } \\
\text { and PCR }\end{array}$ & 77 & 51 & 66.23 & [28] \\
\hline \multirow[t]{2}{*}{21} & Ilam & Jackals & Stray & Microscopic & 56 & 56 & 100 & [29] \\
\hline & & Fox & Stray & Parasitologic & 62 & 62 & 100 & \\
\hline 22 & Khuzestan & Cat & Stray & Parasitologic & 140 & 121 & 86.42 & {$[30]$} \\
\hline 23 & Lorestan & Dog & Stray & Parasitologic & 80 & 68 & 85 & [31] \\
\hline 24 & Mazandaran & Dog & Stray & $\begin{array}{l}\text { Parasitologic } \\
\text { and PCR }\end{array}$ & 100 & 57 & 57 & [32] \\
\hline 25 & Hamedan & Dog & Stray & Parasitologic & 210 & 14 & 6.66 & [33] \\
\hline 26 & Ilam & Cat & Stray & Parasitologic & 50 & 48 & 96 & [34] \\
\hline
\end{tabular}

ID=Identification number, Ref=Reference, $\mathrm{PCR}=$ Polymerase chain reaction

estimated at $80.4 \%$ using a random effect model $(95 \%$ $\mathrm{CI}=70.2-88.8 \%$ ) and a forest plot diagram of the study was generated (Figure-2). A wide variation of these parasites was observed in the included studies (Q statistic $=1107$, degree of freedom $(\mathrm{df})=31, \mathrm{p}<0.0001$, and $\left.\mathrm{I}^{2}=97.2 \%\right)$. The overall prevalence of gastrointestinal parasite in dogs, cats, foxes, and jackals was $57.89 \%$, $90.62 \%, 89.17 \%$, and $97.32 \%$, respectively (Table-2).

The most frequently observed parasite in carnivores was $D$. caninum $(20.45 \%)$, followed by Toxocara spp. (18.81\%), Taenia hydatigena (15.28\%), Mesocestoides lineatus (11.83\%), Diplopylidium nolleri (10.7\%), E. granulosus (10\%), Joyeuxiella (9.65\%), Ancylostoma caninum $(8.77 \%)$, Toxascaris leonina (8.69\%), Rictolaria efinis $(6.66 \%)$, Physaloptera spp. (6.5\%), Macracanthorhynchus hirudinaceus (3.1\%), Taenia taeniaeformis $(2.75 \%)$, Uncinaria stenocephala (2.6\%), Sarcocystis spp. (1.8\%), Eimeria spp. (1.4\%), and Trichuris vulpis $(0.57 \%)$.

By host species, T. hydatigena was the most common parasite $(23.91 \%)$ in dogs, Joyeuxiella $(35.04 \%)$ in cats, and M. lineatus $(51.98 \%)$ in foxes and (39.28\%) jackals (Table-3).
Table-2: Prevalence of gastrointestinal parasitic infections in different species of carnivores in Iran.

\begin{tabular}{lccc}
\hline Carnivores & \multicolumn{3}{c}{ Status of gastrointestinal parasites } \\
\cline { 2 - 4 } & \multicolumn{3}{c}{ N (\%) } \\
\cline { 2 - 4 } & Uninfected & Infected & Total \\
\hline Dog & $648(42.11)$ & $891(57.89)$ & $1539(100)$ \\
Cat & $64(9.38)$ & $618(90.62)$ & $682(100)$ \\
Fox & $30(10.83)$ & $247(89.17)$ & $277(100)$ \\
Jackal & $3(2.68)$ & $109(97.32)$ & $112(100)$ \\
\hline
\end{tabular}

$\mathrm{N}=$ Number of samples

According to the study areas, West Azerbaijan/ Kurdistan/Kermanshah (89.15\%), Isfahan (97.34\%) and Ilam $(100 \%)$ provinces had the highest rate of intestinal parasitic infections in dogs, cats, and foxes (Table-4) [3,13-34]. Moreover, the prevalence of these parasites in jackals in most provinces was $100 \%$.

\section{Discussion}

The present study is the first systematic review of gastrointestinal parasitic infections of carnivores in Iran, providing accurate data for the prevalence of zoonotic parasites from 1997 to 2015 . The overall prevalence rate of gastrointestinal parasitic infections 


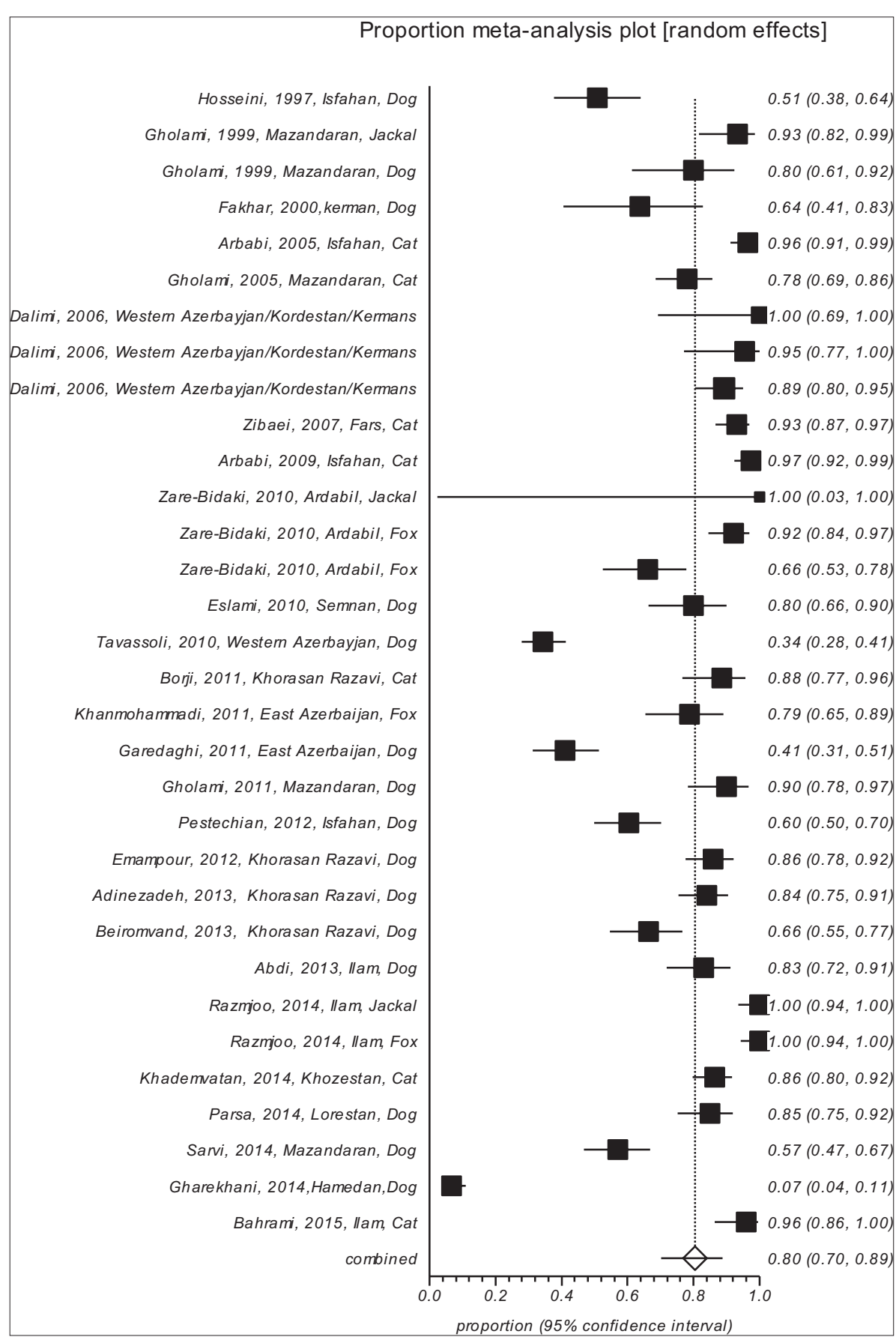

Figure-2: Forest plot diagram of intestinal parasitic infections in carnivores in Iran.

among the studied carnivores in Iran was estimated to be $80 \%(97.32 \%$ jackals, $91.89 \%$ cats, $89.17 \%$ foxes, and $57.89 \%$ dogs).

The prevalence of intestinal parasitic infections in carnivorous has also been reported in other countries such as $90 \%$ in Sri Lanka [8], $71.33 \%$ in Spain [35], and $17.6 \%$ in the Czech Republic [36]. These reported prevalence rates are variable and dependent on a number of factors including different detection methods, geographical climate (temperature and humidity), season, behaviors of the local animal populations, and the type of population of carnivores (stray, shelter, and household) [11,30].

Zoonotic pathogens can cause many different types of problem in human and animals ranging from mild-to-serious infection and even death. Zoonotic diseases are of particular concern for high-risk groups particularly children $[37,38]$. Carnivores, especially dogs and cats, act as the main reservoirs for many zoonotic diseases and play an important role in public health [39].

In Iran, domestic and stray dogs and cats carry the heaviest burden of zoonotic parasites [3]. In many parts of this country, foxes and jackals are also considered as potential sources of infection for humans. Although foxes and jackals generally live in forests and mountainous area, they have been reported proximal to human settlements [29]. As such these animals should be considered in monitoring programs as potential risks for zoonosis due to known interactions with regions of human habitat. 
Table-3: Prevalence of gastrointestinal parasitic infections among foxes, dogs, cats, and jackals in Iran.

\begin{tabular}{lccccc}
\hline Parasite species & \multicolumn{5}{c}{$\mathbf{N}(\mathbf{\%})$} \\
\cline { 2 - 5 } & Dogs (n=1539) & Cats $(\mathbf{n = 6 8 2})$ & Foxes (n=277) & Jackals (n=112) & Total (n=2610) \\
\hline Dipylidium caninum & $260(16.89)$ & $234(34.31)$ & $14(5.05)$ & $26(23.21)$ & $534(20.45)$ \\
Mesocestoides lineatus & $99(6.4)$ & $22(3.81)$ & $144(51.98)$ & $44(39.28)$ & $309(11.83)$ \\
Toxascaris leonina & $160(10.39)$ & $10(1.46)$ & $54(19.49)$ & $3(2.67)$ & $227(8.69)$ \\
Toxocara spp. & $190(12.34)$ & $179(26.24)$ & $97(35.01)$ & $25(22.32)$ & $491(18.81)$ \\
Ancylostoma caninum & $97(6.3)$ & $69(6.14)$ & $31(11.19)$ & $32(28.57)$ & $229(8.77)$ \\
Taenia hydatigena & $368(23.91)$ & $2(0.29)$ & $24(8.66)$ & $5(4.46)$ & $399(15.28)$ \\
Echinococcus granulosus & $225(14.61)$ & - & $5(1.8)$ & $12(10.71)$ & $242(16)$ \\
Taenia ovis & $54(3.5)$ & - & ND (ND) & ND (ND) & $54(2.8)$ \\
Taenia taeniaeformis & $6(0.38)$ & $47(6.89)$ & - & $19(16.96)$ & $72(2.75)$ \\
Taenia multiceps & $74(4.8)$ & - & ND (ND) & $1(0.89)$ & $75(3.89)$ \\
Uncinaria stenocephala & $18(1.16)$ & ND (ND) & $17(6.13)$ & $33(29.46)$ & $68(2.6)$ \\
Joyeuxiella & $4(0.25)$ & $239(35.04)$ & $6(2.16)$ & $3(2.67)$ & $252(9.65)$ \\
Trichuris vulpis & $6(0.38)$ & - & $5(1.8)$ & ND (ND) & $11(0.57)$ \\
Richtolaria efinis & $21(1.36)$ & - & $83(29.96)$ & $70(62.5)$ & $174(6.66)$ \\
Physaloptera & $2(0.13)$ & $147(21.55)$ & $21(7.58)$ & - & $170(6.5)$ \\
Diplopylidium nolleri & - & $73(10.7)$ & - & - & $73(10.7)$ \\
Isospora spp. & $5(0.32)$ & $75(10.99)$ & ND (ND) & $4(3.57)$ & $84(3.21)$ \\
Sarcocystis & $13(0.84)$ & $35(5.13)$ & ND (ND) & ND (ND) & $48(1.83)$ \\
Eimeria & $15(0.97)$ & $21(3.07)$ & $3(N D$ & ND (ND) & $39(1.49)$ \\
Macracanthorhynchus & $6(0.39)$ & ND (ND) & $69(24.9)$ & $6(5.35)$ & $81(3.1)$ \\
hirudinaceus & & & &
\end{tabular}

$\mathrm{ND}=$ Not detected

Table-4: Prevalence of gastrointestinal parasitic infections by areas among dogs, cats, foxes, and jackals in Iran.

\begin{tabular}{|c|c|c|c|c|c|c|c|c|c|}
\hline \multirow[t]{2}{*}{ Province } & \multicolumn{2}{|r|}{ Dog } & \multicolumn{2}{|r|}{ Cat } & \multicolumn{2}{|r|}{ Foxe } & \multicolumn{2}{|r|}{ Jackal } & \multirow[t]{2}{*}{ References } \\
\hline & No. & Pos. (\%) & No. & Pos. (\%) & No. & Pos. (\%) & No. & Pos. (\%) & \\
\hline Ardabil & 59 & $39(66.1)$ & - & - & 89 & $82(92.13)$ & 1 & $1(100)$ & [17] \\
\hline Eastern Azerbaijan & 100 & $41(41)$ & - & - & 52 & $41(78.84)$ & - & - & {$[21,22]$} \\
\hline Fars & - & - & 114 & $106(92.98)$ & - & - & - & - & [16] \\
\hline Hamedan & 210 & $14(6.66)$ & - & - & - & - & - & - & [33] \\
\hline Ilam & 65 & 54 (83.07) & 50 & $48(96)$ & 62 & $62(100)$ & 56 & $56(100)$ & {$[26,29,34]$} \\
\hline Isfahan & 157 & $89(56.68)$ & 226 & 219 (96.9) & - & - & - & - & {$[14,24]$} \\
\hline Kerman & 22 & $14(63.63)$ & - & - & - & - & - & - & {$[13]$} \\
\hline Razavi Khorasan & 277 & $221(79.78)$ & 54 & $46(88.46)$ & - & - & - & - & {$[20,25,27,28]$} \\
\hline Khuzestan & - & - & 140 & $121(86.42)$ & - & - & - & - & [30] \\
\hline Lorestan & 80 & $68(85)$ & - & - & - & - & - & - & [31] \\
\hline Mazandaran & 180 & $126(70.0)$ & 100 & 78 & $(78)$ & - & 45 & $42(93.33)$ & {$[15,23,32]$} \\
\hline Semnan & 50 & $40(80)$ & - & - & - & - & - & - & [18] \\
\hline Western Azerbaijan & 206 & $71(34.4)$ & - & - & - & - & - & - & [19] \\
\hline $\begin{array}{l}\text { Western Azerbaijan/Kurdistan/ } \\
\text { Kermanshah }\end{array}$ & 83 & $74(89.15)$ & - & - & 22 & $21(95.45)$ & 10 & $10(100)$ & {$[3]$} \\
\hline
\end{tabular}

-=Study not conducted, No=Number of samples, Pos=Positive samples

In this systematic review, the investigation of gastrointestinal parasites in carnivores revealed the significant prevalence of six critical zoonotic parasites in Iran including T. canis, E. granulosus, D. caninum, M. lineatus, A. caninum, and M. hirudinaceus. These parasites can cause serious clinical manifestations and diseases in human and should be considered as a major health problem.

\section{D. caninum}

D. caninum is a common intestinal tapeworm of carnivorous that infects humans when they accidentally ingest infected fleas. Linnaeus reported the first known human case of dipylidiasis in 1758. There are more than 120 reports of human dipylidiasis in the world with the majority occurring in children due to either accidental ingestion of infected fleas or contact with saliva of pet animals [40,41]. In this study, $D$. caninum as a zoonotic helminths was the most predominant parasites species in cats $(34.31 \%)$. Moreover, its prevalence was $32.21 \%$ in jackals, $16.89 \%$ in dogs, and $4.05 \%$ in foxes.

\section{M. lineatus}

M. lineatus has a wide distribution in Asia, Europe, and Africa. Reports from Japan, China, and Korea indicate transmission of the parasite to humans can cause diarrhea [42]. In parts of Europe, the adult life stage of this tapeworm occurs with high incidence among foxes (up to 70\%) but rarely in cats and dogs (Germany and Switzerland 2-4\% and England $14 \%)$ [43]. In our study, foxes (51.98\%) were the most infected animals with $M$. lineatus compared to jackals $(39.28 \%)$, dogs $(6.4 \%)$, and cats $(4.69 \%)$. 


\section{E. granulosus/multilocularis}

E. granulosus is one of the major zoonotic parasitic infections in North Africa and the Middle East. Both E. granulosus and E. multilocularis have been reported from these areas $[44,45]$. There are three distinct cycles of $E$. granulosus in Iran:

1. Dogs and livestock (domestic cycle)

2. Dogs and camels (desert cycle)

3. Wild carnivores and wild ruminants (sylvatic cycle).

Hydatid cyst disease is more prevalent in Iran, and it is responsible for nearly $1 \%$ of all admission to surgical wards in Iran hospitals. The majority of cases of human and livestock hydatid cysts have been reported from the Khorasan Razavi Province [46]. Moreover, carnivores are considered as a definitive host for E. multilocularis, acquiring the infection from wild rodents, and can be a main zoonotic risk for alveolar cyst in humans [46,47].

Our review study suggests that the overall prevalence of E. granulosus in dogs, jackals, and foxes are $14.61 \%, 10.71 \%$, and $1.8 \%$, respectively. The global prevalence of echinococcosis in carnivores varies from $1 \%$ to $63.5 \%$ in East Africa, South Africa, South America, East Europe, and China [48,49].

A potential factor for the high prevalence of E. granulosus in Iran might be due to large populations of stray dogs and the lack of continuous comprehensive control programs, especially for farms and around towns $[44,46]$.

\section{Toxocara spp.}

Toxocara species (T. cati, T. canis, and T. leonina) are causative agents of visceral larva migrants in humans. The larva of these parasites can attack the eye cause ocular larva migrants and blindness. Children are the most frequently infected victims of these parasites owing to their close contact with contaminated soil [50]. According to the findings of the current study, the overall prevalence of $T$. canis/cati was $25.58 \%, 12.34 \%, 35.01 \%$, and $22.32 \%$ for cats, dogs, foxes, and jackals, respectively. This considerable infection rate may increase the risk of zoonosis to humans and therefore may play an important role in human toxocariasis in Iran. The lowest and highest prevalence rates of this parasite in foxes were reported from Spain (4.4\%) [51] and Denmark (81\%) [52], respectively. In addition, the minimum and maximum infection rates of $T$. canis in dogs were reported from Czech Republic 6.2\% and Slovak Republic 21.9\%, respectively $[36,53]$.

Whereas, the prevalence of $T$. cati was reported from other countries such as Estonia (48.2\%) [54], Spain (55\%) [55], and Turkey (62.5\%) [56].

\section{M. hirudinaceus}

$M$. hirudinaceus is an acanthocephalan known to infect humans and cause acanthocephaliasis. Although the definitive host for M. hirudinaceus is typically swine, carnivores and humans may act as accidental hosts [57]. Human cases of $M$. hirudinaceus have been reported from China [58] and Thailand [59]. In our study, $0.38 \%$ of dogs, $24.9 \%$ of foxes, and $5.3 \%$ of jackals were infected with the parasite. Although no human infections have been reported in Iran, this high infection rate could increase the possibility of acquiring infection to humans.

\section{A. caninum}

A. caninum is one of the most pathogenic species in carnivores [29]. Larvae of Ancylostoma species cause cutaneous larva migrants or creeping eruption in human. Moreover, these nematodes are responsible for eosinophilic enteritis and unexplained abdominal pain with peripheral eosinophilia in humans [60]. In our study, the prevalence rate of Ancylostoma spp. was similar toxoascaris $(8.77 \%$ and $8.69 \%$, respectively). Due to the high prevalence of $A$. caninum in Jackals, they may be considered as the most important reservoir for cutaneous larva migrants in Iranian people.

\section{Conclusion}

Based on the findings of the current study, the total prevalence of zoonotic intestinal parasites of carnivores in Iran is over $70 \%$. Therefore, serious and continuous preventive measures should be taken into consideration owing to being a public concern in different provinces of Iran.

Control programs including prevention of environmental contamination with carnivore's feces, reduction of the dog, cat, foxes, and jackal population, education program about the zoonotic potential of these parasites, and environmental and ecological modifications can reduce the risk of the transmission infection to human.

\section{Authors' Contributions}

SS, AD, MS, and SG conceptualized the concept of this review paper. MTR, MHK, and ABH statistical advisor and critically reviewed the manuscript. SG, SM, and AS prepared the manuscript. AS and SG assisted in collecting and compiling the resource material. All authors read and approved the final manuscript for publication.

\section{Acknowledgments}

We gratefully acknowledge the supporting the Toxoplasmosis Research Center (TRC) of Mazandaran University of Medical Sciences. The authors are thankful to Vice Chancellor of Research of Mazandaran University of Medical Sciences for financial support (Grant no. 1599).

\section{Competing Interests}

The authors declare that they have no competing interests.

\section{References}

1. Macpherson, C.N. and Torgerson, P.R. (2013) Dogs and Cestode Zoonoses. Dogs, Zoonoses and Public Health. CABI, Oxon, UK. 
2. Kohansal, M.H., Fazaeli, A., Nourian, A., Haniloo, A. and Kamali, K. (2017) Dogs' gastrointestinal parasites and their association with public health in Iran. J. Vet. Res., 61: 189-195

3. Dalimi, A., Sattari, A. and Motamedi, G. (2006) A study on intestinal helminthes of dogs, foxes and jackals in the western part of Iran. Vet. Parasitol., 142: 129-133.

4. Satyal, R., Manandhar, S., Dhakal, S., Mahato, B., Chaulagain, S. and Ghimire, L. (2013) Prevalence of gastrointestinal zoonotic helminths in dogs of Kathmandu, Nepal. Int. J. Infect. Microbiol., 2: 91-94.

5. Chen, J., Xu, M.J., Zhou, D.H., Song, H.Q., Wang, C.R. and Zhu, X.Q. (2012) Canine and feline parasitic zoonoses in China. Parasit. Vectors, 5: 1005-1011.

6. Youn, H. (2009) Review of zoonotic parasites in medical and veterinary fields in the republic of Korea. Korean $J$. Parasitol., 47 Suppl: S133-SS41.

7. Overgaauw, P.A., Van Zutphen, L., Hoek, D., Yaya, F.O., Roelfsema, J., Pinelli, E., Van Knapen, F. and Kortbeek, L.M. (2009) Zoonotic parasites in fecal samples and fur from dogs and cats in the Netherlands. Vet. Parasitol., 163: 115-122.

8. Perera, P., Rajapakse, R. and Rajakaruna, R. (2013) Gastrointestinal parasites of dogs in Hantana area in the Kandy district. J. Natl. Sci. Found. Sri, 41: 81-91.

9. Abere, T., Bogale, B. and Melaku, A. (2013) Gastrointestinal helminth parasites of pet and stray dogs as a potential risk for human health in Bahir Dar town, North-Western Ethiopia. Vet World, 6: 388-392.

10. Arbabi, M. and Hooshyar, H. (2009) Gastrointestinal parasites of stray cats in Kashan, Iran. Trop. Biomed., 26: 16-22.

11. Hosseini, S.H. (1997) Prevalence of Helmentic Infection in Stray Dog in Ardestan City, Iran. $2^{\text {th }}$ Iranian Congress of Parasitology. p193.

12. Gholami, S., Ziaei, H. and Sharif, M. (1999) Intestinal helminth parasites in dog and jackal in inferent areas of Sari in the years 1371-1372. J. Mazandaran Univ. Med. Sci., 9: 1-12.

13. Fakhar, M. and Radfar, M.H. (2000) Survay of Helmentic Infection in Stray Dogs in Kerman and its Health Implications. $3^{\text {th }}$ Iranian Congress of Parasitology. p190.

14. Arbabi, M. and Hooshyar, H. (2005) Prevalence of parasitic infections in cats in Kashsn, Iran. $5^{\text {th }}$ Iranian Congress of Parasitology. p79.

15. Gholami, S., Mobedi, I., Dalimi, A., Ziaei, H., Orouji, A., Mohammadpour, R.A. and Ziapour, S.P. (2005) Survey of Intestinal Parasite in Stary Cats in Sari City in 2004. $5^{\text {th }}$ Iranian Congress of Parasitology. p76.

16. Zibaei, M., Sadjjadi, S.M. and Sarkari, B. (2007) Prevalence of Toxocara cati and other intestinal helminths in stray cats in Shiraz, Iran. Trop. Biomed., 24: 39-43.

17. Zare-Bidaki, M., Mobedi, I., Ahari, S.S., Habibizadeh, S., Naddaf, S. and Siavashi, M. (2010) Prevalence of zoonotic intestinal helminths of canids in Moghan plain, Northwestern Iran. Iran J. Parasitol., 5: 42.

18. Eslami, A., Ranjbar-Bahadori, S., Meshgi, B., Dehghan, M. and Bokaie, S. (2010) Helminth infections of stray dogs from Garmsar, Semnan province, Central Iran. Iran J. Parasitol., 5: 37.

19. Tavasoli, M.J.S., Soltaninejad, F., Rasouli, S. and Etminanfar, R. (2010) Gastrointestinal parasites of pet dogs in Urmia city. Vet. J. (Pajouhesh \& Sazandegi)., 87: 18-24.

20. Borji, H., Razmi, G., Ahmadi, A., Karami, H., Yaghfoori, S. and Abedi, V. (2011) A survey on endoparasites and ectoparasites of stray cats from Mashhad (Iran) and association with risk factors. J. Parasit. Dis., 35: 202-206.

21. Khanmohammadi, M., Fallah, E. and Reyhani-Rad, S. (2011) Epidemiological studies on fauna and preva-lence of parasite helminthes on red fox (Vulpes vulpes) in Sarab district, East Azerbaijan province, Iran. Ann. Biol. Res., 2: 246-251.

22. Gharehdaghi, Y. and Mashaei, S.S. (2011) Prevalence of gastrointestinal helminthic infestation in pet and stray dogs in Tabriz (East-Azerbaijan Province), Iran. J Anim. Vet. $A d v ., 10: 1477-1479$.

23. Gholami, S., Daryani, A., Sharif, M., Amouei, A. and Mobedi, I. (2011) Seroepidemiological survey of helminthic parasites of stray dogs in Sari City, Northern Iran. Pak. J. Biol. Sci., 14: 133-137.

24. Pestechian, N. and Yoosefi, H.A. (2012) Distribution of intestinal worms among stray dogs in Isfahan, Iran. $J$. Isfahan Med. Sch., 29: 1-6.

25. Emampour, S.R. and Nghibi, A. (2012) Prevalence of Intestinal Parasites in Stray Dogs in Mashhad City. $2^{\text {nd }}$ ed. National Cangress of Veteinary Labratory Science Semnan, Iran.

26. Abdi, J., Asadolahi, K., Maleki, M.H. and Ashrafi, A. (2013) Prevalence of helminthes infection of stray dogs in Ilam province. J. Paramed. Sci (JPS)., 4: 47-50.

27. Adinezadeh, A., Beigom Kia, E., Mohebali, M., Shojaee, S., Rokni, M.B., Zarei, Z. and Mowlavi, G. (2013) Endoparasites of stray dogs in Mashhad, Khorasan Razavi province, Northeast Iran with special reference to zoonotic parasites. Iran J. Parasitol., 8: 459.

28. Beiromvand, M., Akhlaghi, L., Massom, S.H.F., Meamar, A.R., Motevalian, A., Oormazdi, H. and Razmjou, E. (2013) Prevalence of zoonotic intestinal parasites in domestic and stray dogs in a rural area of Iran. Prev. Vet. Med., 109: 162-167.

29. Razmjoo, M., Bahrami, A.M. and Shamsollahi, M. (2014) Seroepidemiological survey of important parasitic infections of wild carnivores. Int. J. Adv. Biol. Biomed. Res., 2: 783-792.

30. Khademvatan, S., Abdizadeh, R., Hashemitabar, M., Ghasemi, M. and Tavalla, M. (2014) Stray cats gastrointestinal parasites and its association with public health in Ahvaz City, South Western of Iran. Jundishapur J. Microbiol., 7: 1-6.

31. Parsa, F., Vosoghi, H. and Razani, M. (2014) Study of intestinal parasite of stray dog in Lorestan province of Iran. $A d v$. Environ. Biol., 8: 27-30

32. Sarvi, S., Daryani, A., Sharif, M., Rahimi, M.T., Azami, D., Marhaba, Z., Ahmadpour, E. and Mizani A. (2014) Domestic dog as a human health hazard in north of Iran. $J$. Parasit. Dis., 40: 930-934.

33. Gharekhani, J. (2014) Study on gastrointestinal zoonotic parasites in pet dogs in Western Iran. Türkiye Parazitolo. Derg., 38: 172.

34. Bahrami, A.M. and Shamsi, M. (2015) Zoonotic Parasitic infections of cats in human community: A histopathological study. J. Basic Res. Med. Sci., 2: 49-56.

35. Martínez-Moreno, F., Hernández, S., López-Cobos, E., Becerra, C., Acosta, I. and Martínez-Moreno, A. (2007) Estimation of canine intestinal parasites in Cordoba (Spain) and their risk to public health. Vet. Parasitol., 143: 7-13.

36. Dubná, S., Langrová, I., Nápravník, J., Jankovská, I., Vadlejch, J., Pekár, S. and Fechtner, J. (2007) The prevalence of intestinal parasites in dogs from Prague, rural areas, and shelters of the Czech Republic. Vet. Parasitol., 145: $120-128$.

37. Trevejo, R.T., Barr, M.C. and Robinson, R.A. (2005) Important emerging bacterial zoonotic infections affecting the immunocompromised. Vet. Res., 36: 493-506.

38. Burroughs, T., Knobler, S. and Lederberg, J. (2002) The Emergence of Zoonotic Diseases: Understanding the Impact on Animal and Human Health-Workshop Summary. National Academies Press, Washington, DC.

39. Kruse, H., Kirkemo, A.M. and Handeland, K. (2004) Wildlife as source of zoonotic infections. Emerg. Infect. Dis., 10: 2067-2072.

40. Narasimham, M., Panda, P., Mohanty, I., Sahu, S., Padhi, S. and Dash, M. (2013) Dipylidium caninum infection in a child: A rare case report. Indian J. Med. Microbiol., 31: 82-84.

41. Reid, C., Perry, F., Evans, N. (1992) Dipylidium caninum in 
an infant. Eur. J. Pediatr., 151(7): 502-503.

42. Miyazaki, I. (1991) An illustrated book of helminthic zoonoses. Parasitol. Today, 7: 359.

43. Wirtherle, N., Wiemann, A., Ottenjann, M., Linzmann, H., Van der Grinten, E., Kohn, B., Gruber, A.D. and Clausen, P.H. (2007) First case of canine peritoneal larval cestodosis caused by Mesocestoides lineatus in Germany. Parasitol. Int., 56: 317-320.

44. Sadjjadi, S.M. (2006) Present situation of echinococcosis in the Middle East and Arabic North Africa. Parasitol. Int., 55: S197-S202.

45. Kachani, M. and Heath, D. (2014) Dog population management for the control of human echinococcosis. Acta Trop., 139: 99-108.

46. Rokni, M. (2009) Echinococcosis/hydatidosis in Iran. Iran J. Parasitol., 4: 1-16.

47. Beiromvand, M., Akhlaghi, L., Massom, S.H.F., Mobedi, I., Meamar, A.R., Oormazdi, H., Motevalian, A. and Razmjou, E. (2011) Detection of Echinococcus multilocularis in carnivores in Razavi Khorasan province, Iran using mitochondrial DNA. PLoS Negl. Trop. Dis., 5: e1379.

48. Andererson, F., Ouhelli, H. and Kachani, M. (1997) Cystic echinococcosis in Africa south of the Sahara. Compendium on cystic echinococcosis in Africa and in Middle Eastern Countries with special reference to Morocco. Brigh. Young Univ., 617: 345.

49. Rausch, R. (1995) Life Cycle Patterns and Geographic Distribution of Echinococcus Species. Echinococcus and hydatid disease CAB International, Wallingford. p89-134.

50. Okulewicz, A., Perec-Matysiak, A., Buńkowska, K. and Hildebrand, J. (2012) Toxocara canis, Toxocara cati and Toxascaris leonina in wild and domestic carnivores. Helminthologia, 49: 3-10.

51. Criado-Fornelio, A., Gutierrez-Garcia, L., RodriguezCaabeiro, F., Reus-Garcia, E., Roldan-Soriano, M. and Diaz-Sanchez, M. (2000) A parasitological survey of wild red foxes (Vulpes vulpes) from the province of Guadalajara, Spain. Vet. Parasitol., 92: 245-251.

52. Willingham, A.L., Ockens, N., Kapel, C.M. and Monrad, J. (1996) A helminthological survey of wild red foxes (Vulpes vulpes) from the metropolitan area of Copenhagen. $J$. Helminthol., 70: 259-263.

53. Szabová, E., Juriš, P., Miterpáková, M., Antolová, D., Papajová, I. and Šefčíková, H. (2007) Prevalence of important zoonotic parasites in dog populations from the Slovak Republic. Helminthologia, 44: 170-176.

54. Talvik, H., Moks, E., Mägi, E., Järvis, T. and Miller, I. (2006) Distribution of Toxocara infection in the environment and in definitive and paratenic hosts in Estonia. Acta Vet. Hung., 54: 399-406.

55. Calvete, C., Lucientes, J., Castillo, J.A., Estrada, R., Gracia, M., Peribáñez, M.A. and Ferrer, M. (1998) Gastrointestinal helminth parasites in stray cats from the mid-Ebro Valley, Spain. Vet. Parasitol., 75: 235-240.

56. Yaman, M., Ayaz, E., Gül, A. and Muz, M.N. (2005) Investigation of helminth infections of cats and dogs in the Hatay province. Turkiye Parazitolo. Derg., 30: 200-204.

57. Kassai, T. (2002) Veterinary helminthology. Acribia, SA, London, UK. p258.

58. Zhong, H., Feng, L., Wang, C., Kang, B. and Wang, Z. (1983) Human infection with Macracanthorhynchus hirudinaceus causing serious complications in China. Chin. Med. J., 96: 661-668.

59. Hemsrichart, V., Pichyangkura, C., Chitchang, S. and Vutichamnong, U. (1983) Eosinophilic enteritis due to Macracanthorhynchus hirudinaceus infection: Report of 3 cases. J. Med. Assoc. Thai., 66: 303-310.

60. Ngui, R., Lim, Y.A., Traub, R., Mahmud, R. and Mistam, M.S. (2012) Epidemiological and genetic data supporting the transmission of Ancylostoma ceylanicum among human and domestic animals. PLoS Negl. Trop. Dis., 6: e1522. 